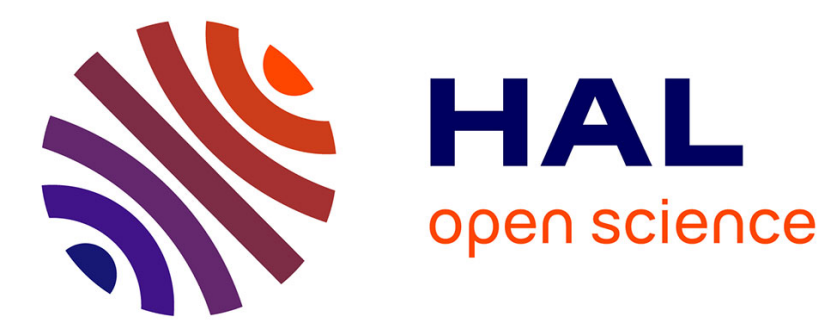

\title{
Excited electronic structure of methylcyanoacetylene probed by VUV Fourier-transform absorption spectroscopy
}

N. Lamarre, B. Gans, L.A. Vieira Mendes, M. Gronowski, J.-C. Guillemin, N. de Oliveira, S. Douin, M. Chevalier, C. Crépin, R. Kolos, et al.

\section{To cite this version:}

N. Lamarre, B. Gans, L.A. Vieira Mendes, M. Gronowski, J.-C. Guillemin, et al.. Excited electronic structure of methylcyanoacetylene probed by VUV Fourier-transform absorption spectroscopy. Journal of Quantitative Spectroscopy and Radiative Transfer, 2016, 182, pp.286-295. 10.1016/j.jqsrt.2016.06.020 . hal-01367230

HAL Id: hal-01367230

https://hal-univ-rennes1.archives-ouvertes.fr/hal-01367230

Submitted on 7 Nov 2016

HAL is a multi-disciplinary open access archive for the deposit and dissemination of scientific research documents, whether they are published or not. The documents may come from teaching and research institutions in France or abroad, or from public or private research centers.
L'archive ouverte pluridisciplinaire HAL, est destinée au dépôt et à la diffusion de documents scientifiques de niveau recherche, publiés ou non, émanant des établissements d'enseignement et de recherche français ou étrangers, des laboratoires publics ou privés. 


\section{Excited electronic structure of methylcyanoacetylene probed by VUV Fourier-transform absorption spectroscopy}

N. Lamarre ${ }^{\mathrm{a}}$, B. Gans ${ }^{\mathrm{a}, *}$, L. A. Vieira Mendes ${ }^{\mathrm{b}}$, M. Gronowskic ${ }^{\mathrm{c}}$, J.-C. Guillemin $^{\mathrm{d}}$, N. De Oliveira ${ }^{\mathrm{e}}$, S. Douin ${ }^{\mathrm{a}}$, M. Chevalier ${ }^{\mathrm{a}}$, C. Crépin ${ }^{\mathrm{a}}$, R. Kołos ${ }^{\mathrm{c}}$, S. Boyé-Péronne ${ }^{\mathrm{a}, *}$

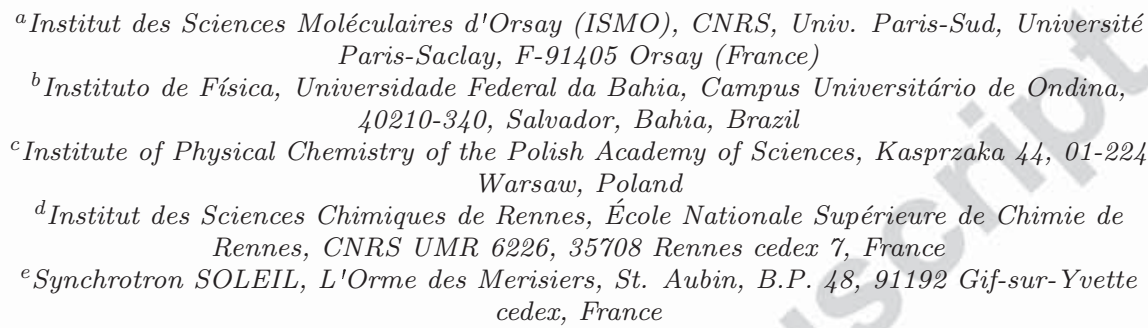

\section{Abstract}

High resolution photoabsorption spectrum of gas-phase methylcyanoacetylene $\left(\mathrm{CH}_{3} \mathrm{C}_{3} \mathrm{~N}\right)$ has been recorded from 44500 to $130000 \mathrm{~cm}^{-1}$ at room temperature with a vacuum ultraviolet Fourier-transform spectrometer on the DESIRS synchrotron beamline (SOLEIL). The absolute photoabsorption cross section in this range is reported for the first time. Valence shell transitions and Rydberg series converging to the ground state $\tilde{\mathrm{X}}^{+}{ }^{2} \mathrm{E}$ of the cation as well as series converging to electronically excited states $\left(\tilde{\mathrm{A}}^{+}{ }^{2} \mathrm{~A}_{1}\right.$ and $\left.\tilde{\mathrm{C}}^{+}\right)$are observed and assigned. Time-dependent density-functional-theory calculations have been performed to support the assignment of the experimental spectrum in the low energy range. A tentative scaling of the previously measured $\mathrm{CH}_{3} \mathrm{C}_{3} \mathrm{~N}^{+}$ion yield by Lamarre et al. (Lamarre et al. J. Mol. Spectrosc. 315 (2015)) is proposed, based on the comparison of the absorption data above the first ionization potential with the observed autoionization structures.

*Corresponding authors: berenger.gans@u-psud.fr, severine.boye-peronne@u-psud.fr 
Keywords: $\mathrm{CH}_{3} \mathrm{C}_{3} \mathrm{~N}$, 2-butynenitrile, cyanopropyne, VUV Fourier-transform spectrometer, synchrotron radiation, Rydberg series, Valence states, absolute absorption cross section.

\section{Introduction}

Methylcyanoacetylene $\left(\mathrm{CH}_{3} \mathrm{C}_{3} \mathrm{~N}\right)$ is a molecule of astrophysical interest, detected in molecular clouds of the interstellar medium (TMC-1 [1], Sgr-B2 [2]), in circumstellar envelopes [3], and anticipated in the atmosphere of Titan (with 5 no firm detection up to now) $[4,5,6,7,8]$. It is the first member of the $\mathrm{CH}_{3}(\mathrm{CC})_{n} \mathrm{CN}$ homologous series; the $n=2$ species (methylcyanodiacetylene) has also been detected in Space [9].

Concerning the spectroscopic fingerprint of this species, the rotational structure of the ground electronic state $\tilde{\mathrm{X}}{ }^{1} \mathrm{~A}_{1}$ has been studied by microwave spectroscopy $[10,11,12,13]$. Infrared spectroscopy studies in the gas phase have been performed $[14,4,6]$ to determine the 12 vibrational modes of this state ( 6 symmetric $\mathrm{a}_{1}$ modes and 6 degenerate e modes in the $\mathrm{C}_{3 \mathrm{v}}$ symmetry group). The unique absorption spectrum involving electronic transitions reported to date ranges in the UV domain from 43000 to $54000 \mathrm{~cm}^{-1}$ and has been measured by Bruston et al. in 1989 [5]. It led to observation of 3 vibrational progressions of a valence-shell electronic transition. Bruston et al. compared this spectrum with the one of cyanoacetylene $\mathrm{HC}_{3} \mathrm{~N}$ in order to partially assign the observed combination bands. They derived vibrational frequency values for the $\nu_{2}(\mathrm{C} \equiv \mathrm{N}$ and $\mathrm{C} \equiv \mathrm{C}$ stretches) and $\nu_{5}$ (C-C stretch) modes of the excited valence state [5]. 20 To our knowledge, no other information is available on the excited electronic states of neutral $\mathrm{CH}_{3} \mathrm{C}_{3} \mathrm{~N}$, neither by experimental VUV spectroscopy nor by $a b$ initio calculation. The only available data concern the cation: in the late seventies the $\mathrm{He}(\mathrm{I})$ and $\mathrm{He}(\mathrm{II})$ photoelectron spectra in the gas-phase have been measured at medium resolution $\left(\sim 160 \mathrm{~cm}^{-1}\right)[15,16]$, and very recently the threshold photoelectron spectrum of $\mathrm{CH}_{3} \mathrm{C}_{3} \mathrm{~N}$ has been recorded by our group at better resolution $\left(\sim 80 \mathrm{~cm}^{-1}\right)[17]$. In addition, the electronic absorption spec- 
trum of methylcyanoacetylene cation has been obtained in $4.5 \mathrm{~K}$ neon matrix by Fulara et al. in 1985 [18]. These experiments allowed to determine the ionization potential and the vibronic structure of the 4 lowest electronic states of 30 the $\mathrm{CH}_{3} \mathrm{C}_{3} \mathrm{~N}^{+}$cation, namely $\left(\tilde{\mathrm{X}}^{+}{ }^{2} \mathrm{E}, \tilde{\mathrm{A}}^{+}{ }^{2} \mathrm{~A}_{1}, \tilde{\mathrm{B}}^{+}{ }^{2} \mathrm{E}\right.$ and $\left.\tilde{\mathrm{C}}^{+}\right)$. Although they relate to the cationic species, they are very useful to understand the excited electronic structure of the neutral molecule, in particular its Rydberg states which resemble the cationic state toward which they converge.

In the present work, we report the first VUV photoabsorption spectrum of methylcyanoacetylene in the gas phase, recorded from 44500 to $130000 \mathrm{~cm}^{-1}$ with a $4 \mathrm{~cm}^{-1}$ spectral resolution thanks to an original Fourier-transform spectrometer.

\section{Experiment}

\subsection{Experimental details}

The experiment was performed at SOLEIL synchrotron facility on the DESIRS beamline [19], using the full bandwidth $(\Delta \sigma / \sigma=7 \%)$ of the undulator source to illuminate a unique VUV Fourier-Transform Spectrometer (FTS) installed in a high-vacuum chamber [20]. The beamline gas filter filled with xenon or argon was employed to remove high harmonics from the synchrotron light beam before it interacts with methylcyanoacetylene. High resolution absorption spectra were recorded at room temperature over consecutive spectral windows corresponding to 21 different undulator settings, and they were spliced together to build the overview spectrum spanning from 44500 to $130000 \mathrm{~cm}^{-1}$. The typical resolution of the spectra recorded in this work was $4 \mathrm{~cm}^{-1}$, which appeared to be sufficient as the narrowest features present in the spectrum have approximately a $15 \mathrm{~cm}^{-1}$ linewidth. Spectral calibration was achieved by recording absorption lines of impurities present in the gas filter. The sample was introduced through a Granville Phillips valve in a constant flow mode into a stainless-steel cylindrical cell ended at both extremities by open thin-capillaries

${ }_{55}(15 \mathrm{~cm}$ long each). The length of the windowless cell was $10 \mathrm{~cm}$. The pres- 
sure in the cell was monitored over the scans by a capacitive gauge located outside the main vacuum chamber. In most experiments the typical pressure inside the windowless cell was in the $0.1-1$ mbar range. Calibration of the absolute photoabsorption cross section was performed using a $\mathrm{MgF}_{2}$ windowed cell and different pressure values to assess the real column density distribution inside the windowless cell. The complete procedure is described in the following paragraph. Synthesis of methylcyanoacetylene was performed prior to the experimental campaign according to the procedure described in Ref. [17] and stored in a freezer. During the measurements, the sample tube was placed in a glass container in which a cooling fluid was circulating via a chiller to ensure a constant working temperature of $+22^{\circ} \mathrm{C}$ and hence a constant vapor pressure of 35 mbar above the liquid.

\subsection{Cross section calibration procedure}

The FTS general method of absolute photoabsorption cross section measurement has already been described [21]. In principle, it requires the recording of a single spectral range using a $\mathrm{MgF}_{2}$ windowed cell in order to infer the absolute absorption cross section for this particular range. The next step involves the windowless cell and allows recording the full spectrum by stitching the individual $7 \%$ bandwidth spectral windows over the desired VUV range. A general calibration curve is determined by recording various absorption spectra over a set of entrance pressures on this particular spectral window. Although in principle the calibration procedure requires only a single spectral window, a first set of scans has been recorded between $44000 \mathrm{~cm}^{-1}$ and $70000 \mathrm{~cm}^{-1}$ at low resolution and moderate signal-to-noise ratio in the windowed cell in order to set a proper absolute scale. Indeed, the range of photoabsorption cross sections for methylcyanoacetylene in the VUV spans more than three orders of magnitude, and such dynamics would have made difficult the determination of a correct calibration curve using a single spectral window. It appeared that the sample was particularly reactive and fragile when exposed to the high flux synchrotron beam in the windowed cell. The recording was tricky as the molecule suffered 
photodestruction and the signal was dropping over a single low resolution scan of a few seconds inside the cell, due to a fast contamination of the cell windows. Nevertheless, it was possible to determine absolute values because the signal affected by the contamination decreases linearly over the acquisition time. Therefore, a normalization on the beginning of the scan was done and a reduction of the data using the background recorded before the scan on an empty cell was performed. No variation of the set pressure was observed, therefore we assumed a constant column density within our error margin over the short time needed to record a spectrum $(\approx 10$ seconds). The windowless spectrum was calibrated onto the windowed cell data up to $70000 \mathrm{~cm}^{-1}$. Above $70000 \mathrm{~cm}^{-1}$, the spectral ranges were normalized on the entrance pressure values and simply connected together as the cross section does not change significantly over this region. In the $44500-55000 \mathrm{~cm}^{-1}$ spectral range, corresponding to the low cross section region, the spectrum is exclusively based upon the data recorded in the windowed cell. Indeed, the required pressure would have been too high to be easily supported by the windowless cell differential pumping system. Note that the experimental linewidth in this region is $\delta \sigma=16 \mathrm{~cm}^{-1}$ for the reasons mentioned above. We believe that most of the absolute photoabsorption cross section uncertainty originates from the difficulty to obtain a constant signal over the time needed to achieve a single scan in the windowed cell. The error estimation is based on the reproducibility of the individual spectral windows at various pressures and also on the non-overlap of two neighbored spectra during the stitching procedure of the different spectral windows. The maximum observed amplitude of the dispersion from scan to scan is $\pm 20 \%$ below $58000 \mathrm{~cm}^{-1}$ and it decreases down to $\pm 10 \%$ in the spectral region above $58000 \mathrm{~cm}^{-1}$. Note that between $55000 \mathrm{~cm}^{-1}$ and $57000 \mathrm{~cm}^{-1}$, due to a lack of time, only a single scan was recorded in the windowless cell with a limited absorption $(\approx 3 \%)$, for this reason the uncertainty may be higher in this particular region where the absorption cross section variation is quite important. 


\section{Quantum chemical calculation methodology}

The present calculations employed the density functional theory (DFT), and were carried out with the Gaussian 09 Rev B.01 software [22]. The CAMB3LYP functional [23] and aug-cc-pVQZ basis set [24, 25] were used. This Coulomb-attenuated exchange-correlation energy functional offers an enhanced description of long-range exchange interactions which improves the predictions of electronic excitation energies of low- $n$ Rydberg states ( $n$ being the principal quantum number). In the first step, geometric parameters of the ground electronic state have been optimized assuming its $\mathrm{C}_{3 \mathrm{v}}$ symmetry. The electronic configuration of the ground electronic state is $[$ core $]\left(1 \mathrm{a}_{1}\right)^{2}\left(2 \mathrm{a}_{1}\right)^{2}\left(3 \mathrm{a}_{1}\right)^{2}\left(4 \mathrm{a}_{1}\right)^{2}$

${ }_{125}\left(5 \mathrm{a}_{1}\right)^{2}(1 \mathrm{e})^{4}(2 \mathrm{e})^{4}\left(6 \mathrm{a}_{1}\right)^{2}(3 \mathrm{e})^{4}$. Subsequently, vertical excitation energies were obtained using the time-dependent DFT approach [26, 27, 28, 29, 30, 31]. All integrals have been calculated with an UltraFine grid option. Standard convergence criteria were applied.

Note that, optimizing the excited electronic state geometries as well as calculating the respective vibrational frequencies, fell beyond the scope of this work.

\section{Results and discussion}

\subsection{Absolute absorption cross section}

The absorption spectrum of methylcyanoacetylene from 44500 to $130000 \mathrm{~cm}^{-1}$ is displayed in Fig. 1 on a logarithmic scale. The vertical scale has been calibrated in absolute absorption cross section using the procedure described in section 2. One can distinguish 4 regions in the spectrum:

- up to $56000 \mathrm{~cm}^{-1}$, the spectrum features weak bands of the valence shell system $\tilde{\mathrm{B}} \leftarrow \tilde{\mathrm{X}}$ only (see below),

- between $56000 \mathrm{~cm}^{-1}$ and $86872 \mathrm{~cm}^{-1}$ (ionization potential towards the $\tilde{\mathrm{X}}^{+}$state of the cation), apart from strong valence shell transitions, the 


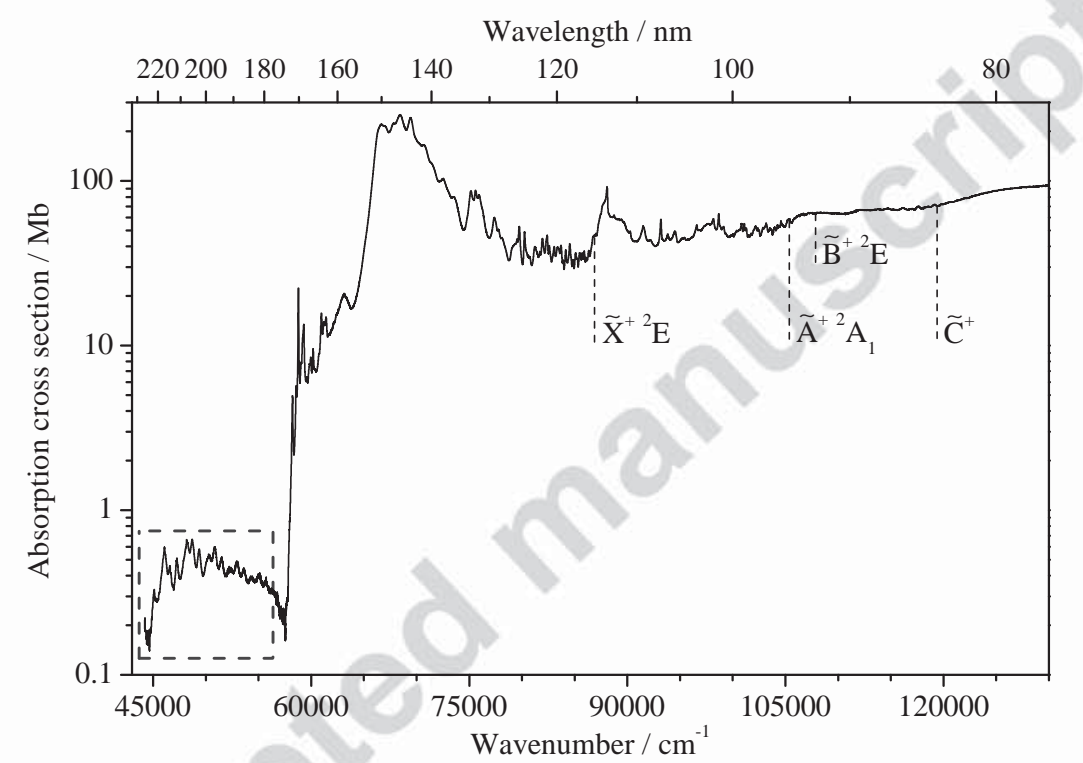

Figure 1: Absolute photoabsorption cross section of methylcyanoacetylene (1 $\mathrm{Mb}=$ $\left.10^{-18} \mathrm{~cm}^{2}\right)$. The vertical dashed lines represent the energetic positions of the lowest electronic states of the cation [17]. The dashed rectangle corresponds to the spectral region which has been previously investigated by Bruston et al. [5] (see text and Fig. 2). 
spectrum is dominated by the Rydberg series converging to the $\tilde{\mathrm{X}}^{+}$state of the cation,

- between $86872 \mathrm{~cm}^{-1}$ and approximately $108000 \mathrm{~cm}^{-1}$, the spectrum consists mostly in Rydberg series converging a priori towards the $\tilde{\mathrm{A}}^{+}$ and/or $\tilde{\mathrm{B}}^{+}$states of the cation,

- above $108000 \mathrm{~cm}^{-1}$, the structures are probably due to Rydberg series converging towards the $\tilde{\mathrm{C}}^{+}$state of the cation.

The assignment of the observed features is explained in the two following sections.

The only published absorption measurement prior to the present work was recorded by Bruston et al. in the UV region $\left(40800-54000 \mathrm{~cm}^{-1}\right)$ [5] materialized by a dotted rectangle in Fig. 1, thus allowing a comparison with our curve in the overlapping region displayed in Fig. 2. As shown in Fig. 2, the positions of the vibrational bands in the region $45000-53000 \mathrm{~cm}^{-1}$ are similar between the two sets of data, although the present study extends the progression beyond $54000 \mathrm{~cm}^{-1}$ which was the monochromator transmission limit of Bruston et al. experiment. Between 44500 and $48000 \mathrm{~cm}^{-1}$, the cross section of the two sets of data are almost identical, but in the high energy range the two traces deviate with a difference beyond our claimed uncertainty $(20 \%)$. A possible contamination in Bruston et al. experiment (mentioned by the authors) could explain this extra absorption that would have been caused by the $\mathrm{O}_{2}$ Schumann-Runge structured absorption bands due to the residual oxygen within their monochromator.

\subsection{Valence state vibrational assignment}

Fig. 3 displays a comparison of the measured absorption spectrum with theoretically (CAM-B3LYP) predicted vertical electronic excitations departing from the $\tilde{\mathrm{X}}^{1} \mathrm{~A}_{1}$ ground electronic state. Noteworthy, the spectrum qualitatively resembles that of $\mathrm{HC}_{3} \mathrm{~N}[32,33]$. As can be seen, computations satisfactorily reproduce the observed valence shell transitions (displayed as purple sticks in 


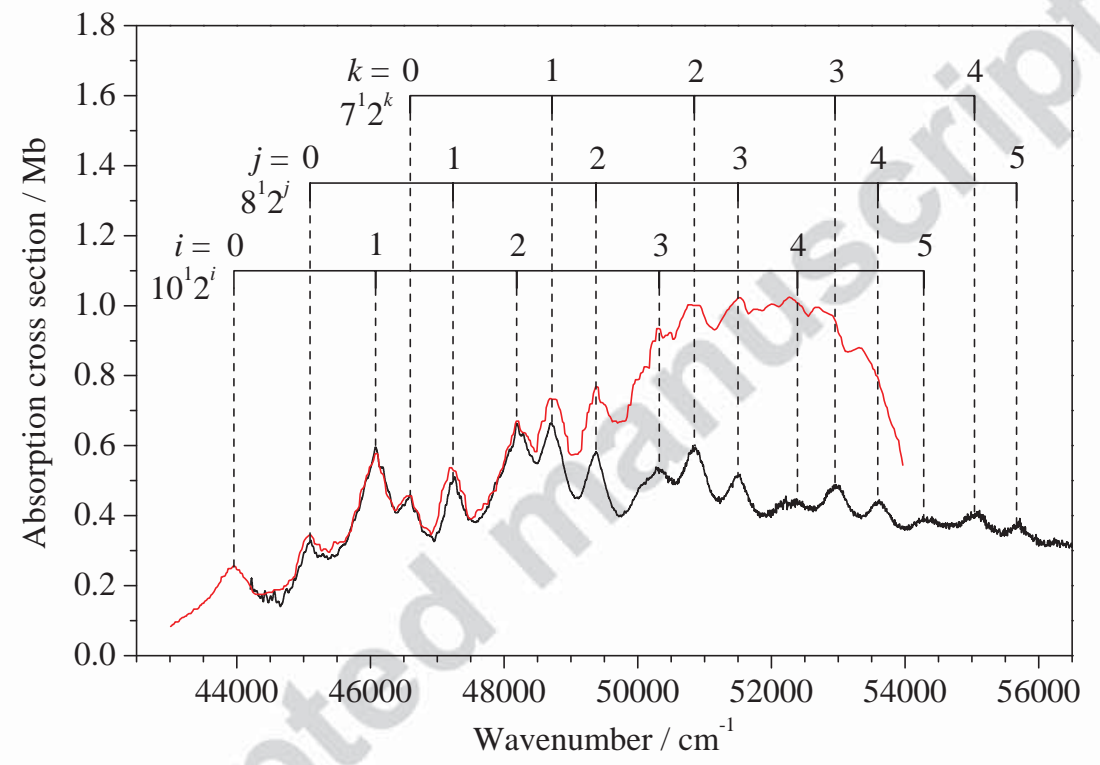

Figure 2: Comparison of the absolute photoabsorption cross section of methylcyanoacetylene between 44500 and $56000 \mathrm{~cm}^{-1}$ measured in this work (black line) and by Bruston et al. [5] (red line). See text for assignment description corresponding to vibrational progressions of the $\tilde{\mathrm{B}}^{1} \mathrm{E} \leftarrow \tilde{\mathrm{X}}^{1} \mathrm{~A}_{1}$ valence shell transition. 


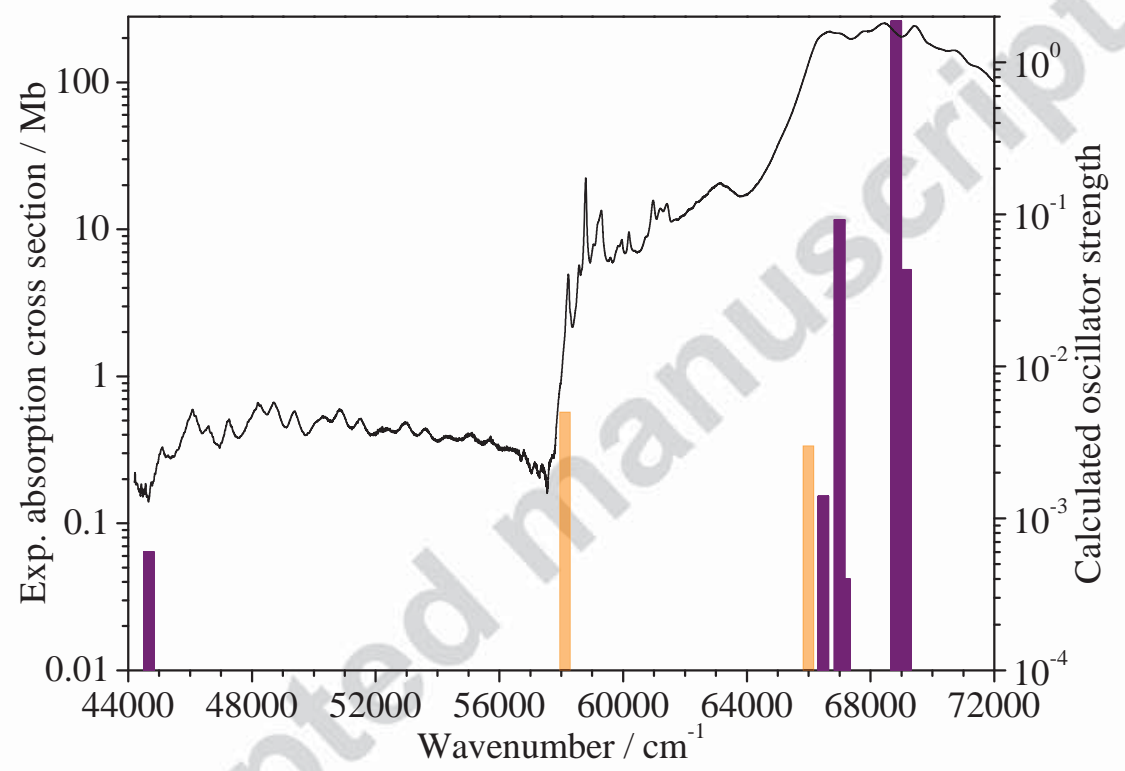

Figure 3: Comparison of the measured methylcyanoacetylene absorption spectrum with theoretically (CAM-B3LYP) predicted vertical electronic excitation energies from the $\tilde{\mathrm{X}}{ }^{1} \mathrm{~A}_{1}$ ground electronic state towards Rydberg states (orange sticks) and valence states (purple sticks). 
Fig. 3) both in energetic positions and in relative intensities. This applies in particular to the strongest band, around $68800 \mathrm{~cm}^{-1}$, recognized as due to $3{ }^{1} \mathrm{~A}_{1} \leftarrow \tilde{\mathrm{X}}{ }^{1} \mathrm{~A}_{1}$ transition (see Table 1 ) and to the lowest energy $\tilde{\mathrm{B}}{ }^{1} \mathrm{E} \leftarrow \tilde{\mathrm{X}}{ }^{1} \mathrm{~A}_{1}$ transition around $44700 \mathrm{~cm}^{-1}$.

Table 1: CAM-B3LYP-derived vertical electronic excitations originating from the $\tilde{\mathrm{X}}{ }^{1} \mathrm{~A}_{1}$ ground electronic state of methylcyanoacetylene. Note that the labelling of the states refers to the state order at the neutral ground state geometry. The $3 \mathrm{e}, 1 \mathrm{e}^{*}$ and $6 \mathrm{a}_{1}$ orbitals correspond to the highest occupied molecular orbital, the lowest unoccupied molecular orbital, and the orbital of the lone electron pair of the nitrogen atom, respectively.

\begin{tabular}{l|c|r|r}
$\begin{array}{l}\text { Upper } \\
\text { state }\end{array}$ & $\begin{array}{c}\text { Orbital } \\
\text { excitation }\end{array}$ & $\begin{array}{r}\text { Vertical transition } \\
\text { energies }\left[\mathrm{cm}^{-1}\right]\end{array}$ & $\begin{array}{r}\text { Predicted } \\
\text { Oscillator strengths }\end{array}$ \\
\hline $1^{1} \mathrm{~A}_{2}$ & $3 \mathrm{e} \rightarrow 1 \mathrm{e}^{*}$ & $43.0 \times 10^{3}$ & $0 \times 10^{-4}$ \\
\hline $1^{1} \mathrm{E}(\tilde{\mathrm{B}})$ & $3 \mathrm{e} \rightarrow 1 \mathrm{e}^{*}$ & $44.7 \times 10^{3}$ & $5 \times 10^{-3}$ \\
\hline $2{ }^{1} \mathrm{E}$ & $3 \mathrm{e} \rightarrow 3 \mathrm{~s}$ & $58.1 \times 10^{3}$ & 0 \\
\hline $2{ }^{1} \mathrm{~A}_{2}$ & $2 \mathrm{e} \rightarrow 1 \mathrm{e}^{*}$ & $64.0 \times 10^{3}$ & $3 \times 10^{-3}$ \\
\hline $3{ }^{1} \mathrm{E}$ & $3 \mathrm{e} \rightarrow 3 \mathrm{p}$ & $66.0 \times 10^{3}$ & $1 \times 10^{-3}$ \\
\hline $4{ }^{1} \mathrm{E}$ & $2 \mathrm{e} \rightarrow 1 \mathrm{e}^{*}$ & $66.5 \times 10^{3}$ & $9 \times 10^{-2}$ \\
\hline $2^{1} \mathrm{~A}_{1}$ & $3 \mathrm{e} \rightarrow 2 \mathrm{e}^{*}$ & $67.0 \times 10^{3}$ & $4 \times 10^{-4}$ \\
\hline $5{ }^{1} \mathrm{E}$ & $3 \mathrm{e} \rightarrow 2 \mathrm{e}^{*}$ & $67.2 \times 10^{3}$ & 0 \\
\hline $3^{1} \mathrm{~A}_{2}$ & $3 \mathrm{e} \rightarrow 2 \mathrm{e}^{*}$ & $67.3 \times 10^{3}$ & 1.9 \\
\hline $3{ }^{1} \mathrm{~A}_{1}$ & $3 \mathrm{e} \rightarrow 1 \mathrm{e}^{*}$ & $68.8 \times 10^{3}$ & $4 \times 10^{-2}$ \\
\hline $6{ }^{1} \mathrm{E}$ & $6 \mathrm{a}_{1} \rightarrow 1 \mathrm{e}^{*}$ & $69.1 \times 10^{3}$ & \\
\hline
\end{tabular}

The latter one, even though formally symmetry-allowed, is in fact closely similar to the forbidden $\mathrm{B}^{1} \Delta \leftarrow \mathrm{X}^{1} \Sigma^{+}$system of $\mathrm{HC}_{3} \mathrm{~N}$, since the considered chromophores of both molecules consist of essentially the same $\mathrm{C}_{3} \mathrm{~N}$ chains. This explains its weak intensity.

For the vibronic structure of this first observable electronic absorption system of $\mathrm{CH}_{3} \mathrm{C}_{3} \mathrm{~N}(\tilde{\mathrm{B}} \leftarrow \tilde{\mathrm{X}})$, Bruston et al. proposed a partial assignment involving the $\nu_{2}(\mathrm{C} \equiv \mathrm{N}, \mathrm{C} \equiv \mathrm{C}$ stretches in phase $)$ vibrational progression coupled 
with either one quantum of $\nu_{11}$ (CCCCN skeleton bend) or a combination of one quantum of $\nu_{11}$ and one quantum of $\nu_{5}$ (C-C stretches, opposite phases). Indeed, isotopic shifts measured in the UV spectrum of cyanoacetylene are consistent with those expected for $\nu_{2}$ [34]. The combination of the $\nu_{2}$ and $\nu_{11}$ vibrational modes was chosen by the authors by analogy with cyanoacetylene [35]. The combination of $\nu_{11}$ with $\nu_{5}$, proposed by Bruston et al., was suggested by the values of vibrational frequencies found for the ground electronic state of $\mathrm{CH}_{3} \mathrm{C}_{3} \mathrm{~N}$. A third progression detected by Bruston et al. remained unassigned.

Here we propose a different but complete assignment for the three $\nu_{2}$-based progressions observed in the absorption spectrum. First, we suggest the mode $\nu_{10}\left(499 \mathrm{~cm}^{-1}\right.$ in the ground state [17]) as a better candidate than $\nu_{11}\left(339 \mathrm{~cm}^{-1}\right.$ in the ground state [17]) for the lowest energy "false origin". Indeed, that latter mode involves the $\mathrm{CH}_{3} \mathrm{CC}$ part of the molecule, while the $\mathrm{CCCCN}$ skeleton bending $\nu_{10}$ is similar to the vibration around $500 \mathrm{~cm}^{-1}$ observed for the ground electronic state of $\mathrm{HC}_{3} \mathrm{~N}$ [35], of the cyanopolyynic chains such as $\mathrm{HC}_{5} \mathrm{~N}$ [36], $\mathrm{C}_{2} \mathrm{~N}_{2}$ [37], $\mathrm{C}_{4} \mathrm{~N}_{2}$ [38], and is always active in the respective $\mathrm{B} \leftarrow \mathrm{X}$ transitions. Taking into account the measured energy differences between the origins of the three progressions, as well as the fact that the discussed ground-state bending frequencies are reduced by approximately $100 \mathrm{~cm}^{-1}$ in the second excited state of the above mentioned molecules, the origins of the two remaining progressions should involve modes of frequencies around $1550 \mathrm{~cm}^{-1}$ and around $3050 \mathrm{~cm}^{-1}$. These we propose to identify as, respectively, $\nu_{8}\left(\mathrm{CH}_{3}\right.$ antisymmetric deformation) and $\nu_{7}\left(\mathrm{CH}_{3}\right.$ antisymmetric stretch) [17], both of e symmetry. Analogous chain-stretching mode progressions, gaining strength via coupling to e-symmetry modes, have been recently observed for the $\tilde{B}-\tilde{X}$ system of $\mathrm{CH}_{3} \mathrm{C}_{5} \mathrm{~N}$ [39]. This reasoning allows for expecting the vibrationless origin of $\tilde{\mathrm{B}}-\tilde{\mathrm{X}}$ within the $43400-43600 \mathrm{~cm}^{-1}$ range, in reasonable agreement with our CAM B3LYP prediction of $44700 \mathrm{~cm}^{-1}$ (see Table 1).

The relative energies with respect to their origins of the three observed $\nu_{2}$ progression bands of the $\tilde{\mathrm{B}}^{1} \mathrm{E} \leftarrow \tilde{\mathrm{X}}^{1} \mathrm{~A}_{1}$ transition are plotted in Fig. 4 against the $v_{2}$ quantum number. The data points exhibit a linear behaviour which 

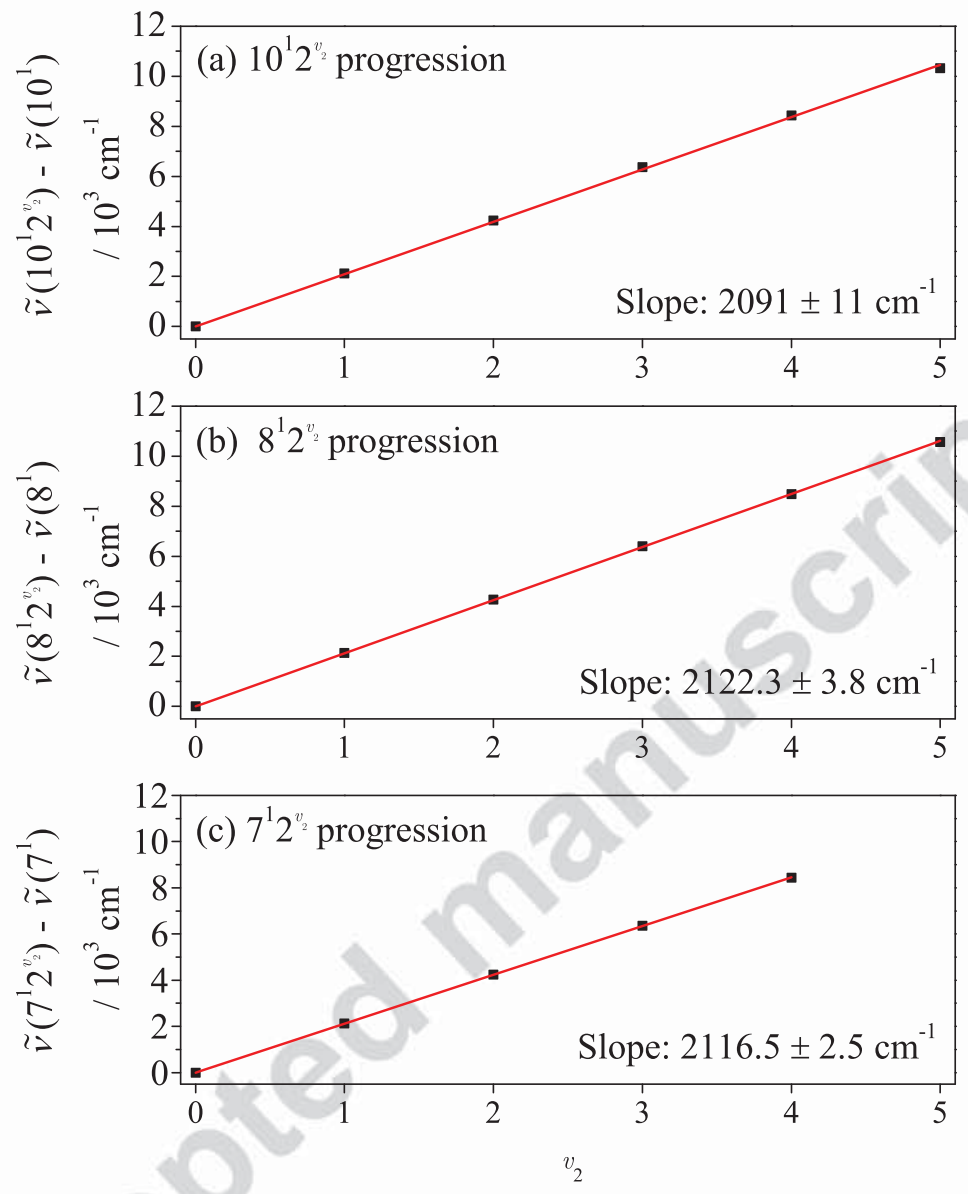

Figure 4: Plots of the $2^{v}$ level wavenumbers against the $v_{2}$ vibrational quantum number for the three observed $\nu_{2}$ progressions in combination with $10^{1}$ (panel (a)), $8^{1}$ (panel (b)) and $7^{1}$ (panel (c)) with respect to their origin. The black squares are the experimental data and the red lines the linear fits.

implies that the anharmonic parameter of the $\nu_{2}$ mode (anharmonicity constant $x_{2,2}$ ) can be neglected in a first approximation. From a linear fit of the three sets of data, we derived the following slopes: $2091 \mathrm{~cm}^{-1}, 2122.3 \mathrm{~cm}^{-1}$, and $2116.5 \mathrm{~cm}^{-1}$, for the $\nu_{2}$ progressions involving, respectively, a quantum of either $\nu_{10}, \nu_{8}$ or $\nu_{7}$. Anharmonicity constants $x_{2,8}$ and $x_{2,7}$ are therefore smaller than 
$x_{2,10}$, which is quite an intuitive result. Indeed, the vibrational modes localised mainly within the methyl group $\left(\nu_{8}\right.$ and $\left.\nu_{7}\right)$ are not expected to interact strongly with $\nu_{2}$, this latter mode being responsible mostly for the CN stretching.

\subsection{Rydberg series assignments}

Energies of the lowest $\mathrm{CH}_{3} \mathrm{C}_{3} \mathrm{~N}^{+}$electronic states, to which the observed bands of Rydberg series converge, have been recently measured and published by our group [17]. Pertinent information for the present work is reported in Table 2.

Table 2: Ionization potentials of $\mathrm{CH}_{3} \mathrm{C}_{3} \mathrm{~N}$ towards the four lowest electronic states of the cation, and cationic harmonic vibrational frequencies of the main active modes upon ionization from Ref. [17]. All values are in $\mathrm{cm}^{-1}$ and the uncertainties are given in parentheses. Note that the notation of the neutral species (in the $\mathrm{C}_{3 \mathrm{v}}$ point group) is used for the vibrational mode labelling of the cationic states (see Ref. [17] for details).

\begin{tabular}{c|c|l|c} 
Cationic state & $E_{\mathrm{I}} / h c$ & Active mode and description & Harmonic frequency \\
\hline$\tilde{\mathrm{X}}^{+2} \mathrm{E}$ & $86872(20)$ & $\nu_{2}(\mathrm{C} \equiv \mathrm{N}, \mathrm{C} \equiv \mathrm{C}$ stretches in phase $)$ & $2178(20)$ \\
\hline$\tilde{\mathrm{A}}^{+2} \mathrm{~A}_{1}$ & $105354(20)$ & $\nu_{2}(\mathrm{C} \equiv \mathrm{N}, \mathrm{C} \equiv \mathrm{C}$ stretches in phase $)$ & $2246(30)$ \\
& & $\nu_{6}(\mathrm{C}-\mathrm{C}$ stretches in phase $)$ & $655(30)$ \\
\hline$\tilde{\mathrm{B}}^{+2} \mathrm{E}$ & $107848(20)$ & $\nu_{5}(\mathrm{C}-\mathrm{C}$ stretches opposite phase $)$ & $1132(20)$ \\
\hline$\tilde{\mathrm{C}}^{+}$ & $119390(50)$ & $\nu_{8}\left(\mathrm{CH}_{3}\right.$ antisym. deformation $)$ & $1586(40)$ \\
\hline
\end{tabular}

The difficulty in assigning the absorption spectrum comes from the high density of states and the fact that these states are not fully resolved. Here, we based our assignment on our recent analysis of the TPES spectrum of $\mathrm{CH}_{3} \mathrm{C}_{3} \mathrm{~N}$ [17]. In this study we determined which vibrational modes are active upon ionization towards each cationic electronic state. These results give us a hint about which vibrational modes can be observed in the transitions towards the Rydberg states. Indeed the well-known property of Rydberg states is to have a similar geometry to the cationic state towards which the Rydberg series converge. 
From this consideration, one can assume that the Rydberg series converging to $\tilde{\mathrm{X}}^{+}, \tilde{\mathrm{A}}^{+}, \tilde{\mathrm{B}}^{+}$and $\tilde{\mathrm{C}}^{+}$will exhibit vibrational structures involving mainly the vibrational modes reported in Table 2 . Note that we only take into account the vibrational modes which are the most active upon ionization [17].

Finally, to assign the Rydberg series we use plots of the absorption cross section against the effective principal quantum number, $n^{*}\left(n^{*}=n-\delta\right.$, where $n$ is the principal quantum number and $\delta$ the quantum defect), following the well-known Rydberg formula $\left(\tilde{\nu}=E_{\mathrm{i}} / h c-R /(n-\delta)^{2}\right.$, where $E_{\mathrm{i}} / h c$ is the ionization potential in $\mathrm{cm}^{-1}$ and $R$ the Rydberg constant for $\mathrm{CH}_{3} \mathrm{C}_{3} \mathrm{~N}$ in $\mathrm{cm}^{-1}$ ). In Appendix A, the plot corresponding to the Rydberg series converging to the ground vibronic state of the cation $\left(\tilde{\mathrm{X}}^{+2} \mathrm{E} v^{+}=0\right)$ is displayed as an example (the other plots are not presented in this paper). The aim of this kind of plot is to recognize the peaks which are present approximately at the same quantum defect value $\left(\delta=n^{*}-n\right.$, thus the decimal part of $\left.n^{*}\right)$, provided no coupling between valence and Rydberg states exists.

Following this procedure for all the ionization limits $\left(\tilde{\mathrm{X}}^{+2} \mathrm{E} v^{+}=0, \tilde{\mathrm{X}}^{+2} \mathrm{E} v_{2}^{+}=\right.$ $\left.2501, \tilde{\mathrm{A}}^{+2} \mathrm{~A}_{1} v^{+}=0, \ldots\right)$, we assign most of the observed structures. The corresponding assignment is summarized in Table 3 and the origins of each Rydberg state $(v=0)$ are labeled in Figs. 5, 6 and 7. The quantum defects obtained for the Rydberg series allow us to deduce the s, p or d character of the series by assuming that $n \mathrm{~s}, n \mathrm{p}$ and $n$ d series usually have quantum defects of about 1 , 0.5 and $<0.2$, respectively.

In Fig. 5, the absorption spectrum of $\mathrm{CH}_{3} \mathrm{C}_{3} \mathrm{~N}$ between 60000 and $88000 \mathrm{~cm}^{-1}$ is displayed with 3 assigned Rydberg series converging to the adiabatic ionization potential of the $\tilde{\mathrm{X}}^{+2} \mathrm{E}$ electronic ground state $\left(86872 \mathrm{~cm}^{-1}[17]\right)$. The $n \mathrm{~s}$, $n \mathrm{p}$ and $n \mathrm{~d}$ Rydberg series have averaged quantum defects of $0.94,0.63$, and 0.13 , respectively. The Rydberg states are indicated in this spectrum by dashed lines and labeled $n \mathrm{~s} 0^{0}\left[\tilde{\mathrm{X}}^{+}\right], n \mathrm{p} 0^{0}\left[\mathrm{X}^{+}\right]$and $n \mathrm{~d} 0^{0}\left[\mathrm{X}^{+}\right]$, respectively. The vibrationally excited Rydberg states are not displayed in Fig. 5 for clarity (see Table 3 for detailed assignment and individual quantum defect values and figures provided as supplementary material). Note that the quantum defect of the 


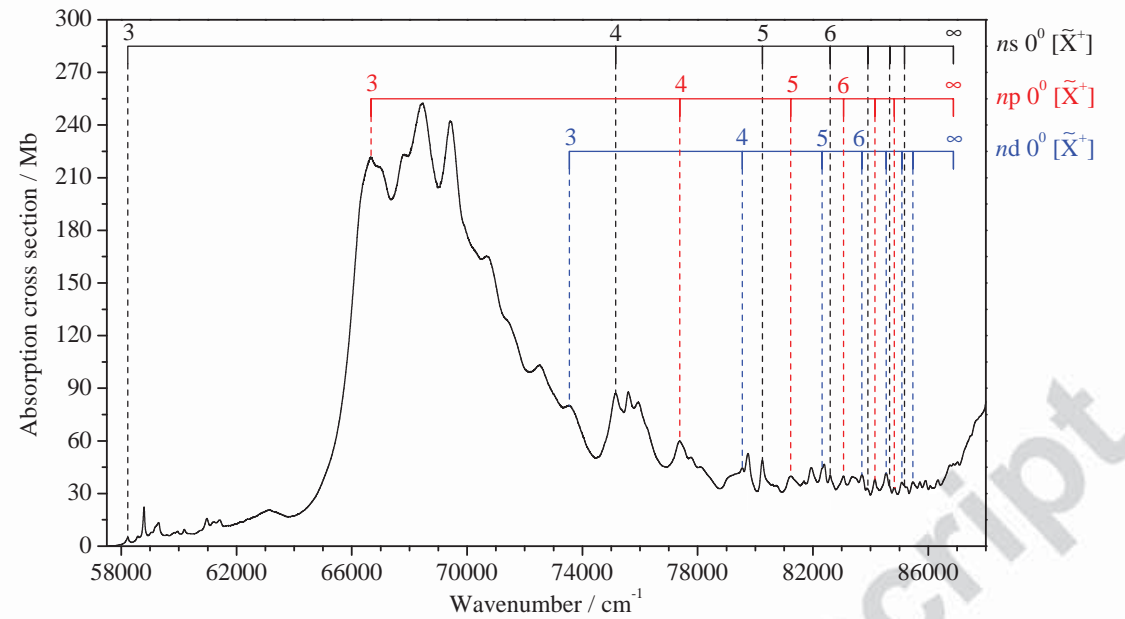

Figure 5: Absorption spectrum of methylcyanoacetylene between 60000 and $88000 \mathrm{~cm}^{-1}$ with the assignment corresponding to the Rydberg series converging to the $\tilde{\mathrm{X}}^{+}{ }^{2} \mathrm{E}\left(v^{+}=0\right)$ cationic state. The $n \mathrm{~s}, n \mathrm{p}$ and $n \mathrm{~d}$ series are reported in black, red and blue, respectively.

3s state is slightly higher (1.04) than the other members of this series (0.93) (see Table 3). With our modest calculations, the transition denoted $2{ }^{1} \mathrm{E} \leftarrow \tilde{\mathrm{X}}^{1} \mathrm{~A}_{1}$ in Table 1 is securely interpreted as the one occurring between the highest occupied molecular orbital and the 3s Rydberg orbital, and it unambiguously corresponds to the system of vibrationally resolved bands observed in the 58000 - $64000 \mathrm{~cm}^{-1}$ range. Its relatively high strength may stem from the HerzbergTeller effect, namely an "intensity borrowing" from $3{ }^{1} \mathrm{~A}_{1} \leftarrow \tilde{\mathrm{X}}^{1} \mathrm{~A}_{1}$ transition that was not accounted for in the present calculations. The $3 \mathrm{p}\left[\tilde{\mathrm{X}}^{+}\right]$and $3 \mathrm{~d}$ $\left[\tilde{\mathrm{X}}^{+}\right]$states are also in the range of this valence transition. Thus, it is very difficult to unambiguously conclude on their location without taking into account a possible Rydberg-valence interaction. Here, we choose to assign the structures which correspond to the closest quantum defect value of the corresponding series. Note that the calculated wavenumber for the transition towards the $3 p$ states only differs by $670 \mathrm{~cm}^{-1}$ (see Tables 1 and 2).

The Rydberg series converging to the first excited electronic state of $\mathrm{CH}_{3} \mathrm{C}_{3} \mathrm{~N}^{+}$ ${ }_{280}\left(\tilde{\mathrm{A}}^{+2} \mathrm{~A}_{1}\left(v^{+}=0\right), I P=105354 \mathrm{~cm}^{-1}[17]\right)$ are depicted in Fig. 6 (see Table 3 
for the assignment of the vibrationally excited Rydberg states and figures provided as supplementary material). The average values of the quantum defects

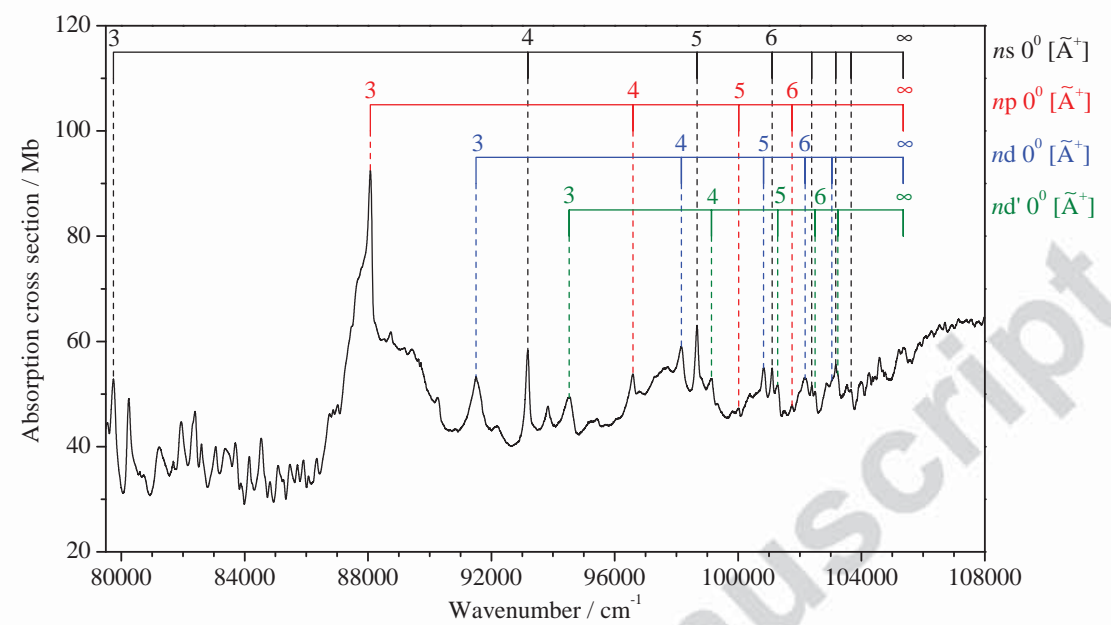

Figure 6: Absorption spectrum of methylcyanoacetylene between 79500 and $108000 \mathrm{~cm}^{-1}$ with the assignment corresponding to the Rydberg series converging to the $\tilde{\mathrm{A}}^{+}{ }^{2} \mathrm{~A}_{1}\left(v^{+}=0\right)$ cationic state. The $n \mathrm{~s}, n \mathrm{p}, n \mathrm{~d}$ and $n \mathrm{~d}^{\prime}$ series are reported in black, red, blue and green, respectively.

of the $n \mathrm{~s}, n \mathrm{p}, n \mathrm{~d}$ and $n \mathrm{~d}^{\prime}$ series are $0.94,0.47,0.11$ and -0.19 , respectively. Individual quantum defects are reported in Table 3. Note that in this region, no Rydberg series converging to the $\tilde{\mathrm{B}}^{+2} \mathrm{E}$ electronic state of the cation has been identified.

The absorption spectrum in the $108000-120000 \mathrm{~cm}^{-1}$ range is displayed in Fig. 7. Only one $n$ d Rydberg series converging to the $\tilde{\mathrm{C}}^{+}$electronic state of $\mathrm{CH}_{3} \mathrm{C}_{3} \mathrm{~N}^{+}$is identified. In this region, the Rydberg states are quite broad indicating a short lifetime of these states. This feature is very similar to that encountered in transitions towards the $\tilde{\mathrm{C}}^{+}$state of the cation in the thresholdphotoelectron spectrum (TPES) [17]. The observed $n$ d series has an average quantum defect of 0.15 . Origin terms with a principal quantum number from 4 to 8 are presented in Fig. 7 . The $n=3$ term can be associated with four peaks between 105500 and $106500 \mathrm{~cm}^{-1}$ : $105570,105865,106065$ and $106265 \mathrm{~cm}^{-1}$. 


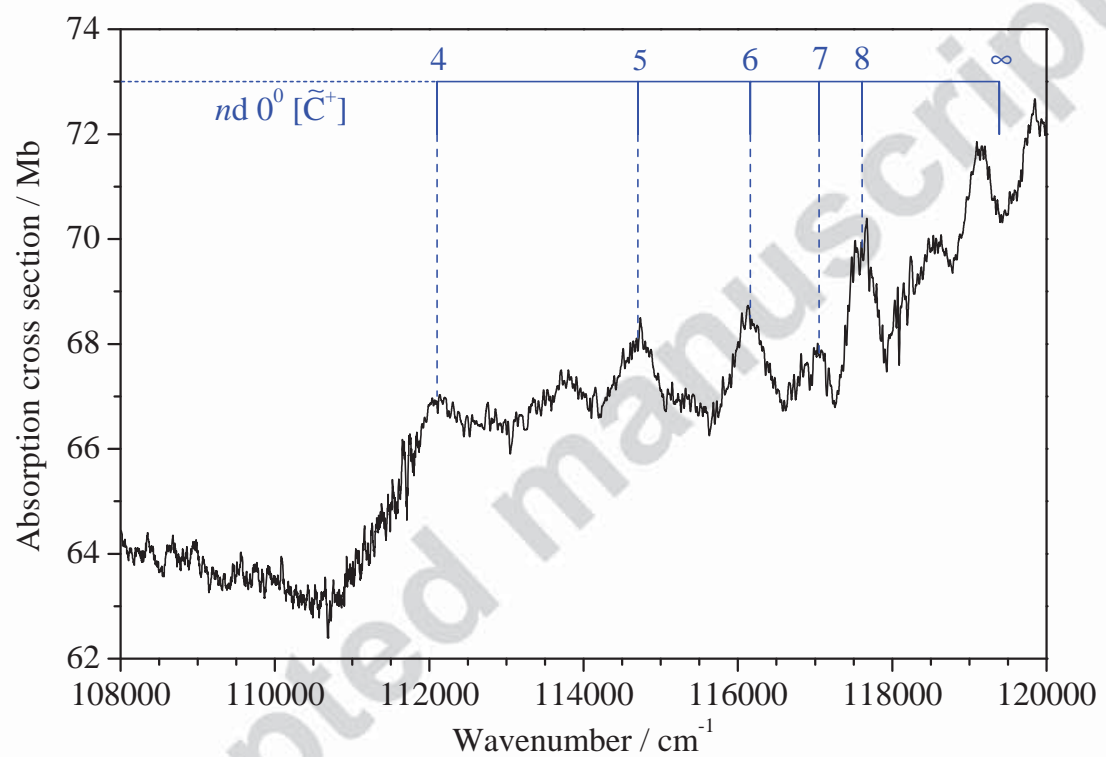

Figure 7: Absorption spectrum of methylcyanoacetylene between 108000 and $120000 \mathrm{~cm}^{-1}$ with the assignment corresponding to the Rydberg series converging to the $\tilde{\mathrm{C}}^{+}\left(v^{+}=0\right)$ cationic state. The $n$ d series is reported in blue. 
If we assign this term with one of these peaks, we find quantum defects of 0.18 , $0.15,0.13$ and 0.11 , respectively. No conclusion can be drawn from the quantum defect value only for the $n=3$ Rydberg state hence it is not assigned here. The most active mode upon ionization towards the $\tilde{\mathrm{C}}^{+}$state is the $\nu_{8}^{+}$with a harmonic frequency of $1586 \mathrm{~cm}^{-1}$ [17]. In the TPES, a long progression along this mode was observed. Nevertheless, the absorption spectrum seems to possess only one series converging to the ground vibrational state of the $\tilde{\mathrm{C}}^{+}$electronic state. Only one of the assigned Rydberg states $\left(4 \mathrm{~d} 8_{0}^{1}\left[\tilde{\mathrm{C}}^{+}\right]\right)$seems to exhibit one vibrational state which might be assigned to the $\nu_{8}$ mode. However, since the bands are broader in this region, it is difficult to conclude.

Our tentative assignment of the different Rydberg series described above is summarized in Table 3. Only 74 over more than 130 observed bands have been assigned in this work and high level $a b$ initio calculations are needed to support a complete spectral analysis and to investigate the possible Rydberg-valence interactions.

\subsection{Photoionization cross section}

Based on the quasi perfect match observed between the absorption band intensities and the autoionization structure intensities observed in the $\mathrm{CH}_{3} \mathrm{C}_{3} \mathrm{~N}^{+}$ ion yield in Ref. [17] in the $100000-105000 \mathrm{~cm}^{-1}$ region, it is reasonable to assume that the photoionization quantum yield is close to unity in this spectral range. Indeed, it is quite unlikely that other processes (photodissociation for instance) would present exactly the same structures with the same relative intensities in this range. Within this assumption, we have scaled the photoionization yield of the $\mathrm{CH}_{3} \mathrm{C}_{3} \mathrm{~N}^{+}$parent ion [17] on an absolute cross section scale and the resulting spectrum is displayed in Fig. 8. Note that this scaling only gives an upper limit estimate of the ionization cross section.

Between the first ionization potential and c.a. $100000 \mathrm{~cm}^{-1}$, the difference between the two curves is due to neutral dissociation processes which compete with ionization. Above $105000 \mathrm{~cm}^{-1}$, the photoionization cross section decreases whereas the photoabsorption cross section increases. This can eas- 
Table 3: Position of the observed peaks in the absorption spectrum with the corresponding assignment. For Rydberg series converging to the electronic states of $\mathrm{CH}_{3} \mathrm{C}_{3} \mathrm{~N}^{+}$, the quantum defect $\delta$ is given in parentheses. All values are in $\mathrm{cm}^{-1}$.

\begin{tabular}{|c|c|c|c|c|c|}
\hline$\tilde{\nu}$ & Assignment $(\delta)$ & $\tilde{\nu}$ & Assignment $(\delta)$ & $\tilde{\nu}$ & Assignment $(\delta)$ \\
\hline 58230 & $3 \mathrm{~s} 0^{0}\left[\mathrm{X}^{+}\right](1.04)$ & 85260 & $6 \mathrm{p} 2^{1}\left[\mathrm{X}^{+}\right](0.62)$ & 99810 & $4 \mathrm{~d}^{\prime} 6^{1}\left[\mathrm{~A}^{+}\right](-0.21)$ \\
\hline 60190 & $3 \mathrm{~s} 2^{1}\left[\mathrm{X}^{+}\right](1.05)$ & 85471 & $9 \mathrm{~d} 0^{0}\left[\mathrm{X}^{+}\right](0.15)$ & 100020 & $5 \mathrm{p} 0^{0}\left[\mathrm{~A}^{+}\right](0.46)$ \\
\hline 66670 & $3 \mathrm{p} 0^{0}\left[\mathrm{X}^{+}\right](0.67)$ & 85900 & $6 \mathrm{~d} 2^{1}\left[\mathrm{X}^{+}\right](0.10)$ & 100383 & $4 \mathrm{~d} 2^{1}\left[\mathrm{~A}^{+}\right](0.10)$ \\
\hline 73568 & $3 \mathrm{~d} 0^{0}\left[\mathrm{X}^{+}\right](0.13)$ & 86072 & $7 \mathrm{~s} 2^{1}\left[\mathrm{X}^{+}\right](0.93)$ & 100825 & $5 \mathrm{~d} 0^{0}\left[\mathrm{~A}^{+}\right](0.08)$ \\
\hline 75155 & $4 \mathrm{~s} 0^{0}\left[\mathrm{X}^{+}\right](0.94)$ & 86340 & $7 \mathrm{p} 2^{1}\left[\mathrm{X}^{+}\right](0.64)$ & 101104 & $6 \mathrm{~s} 0^{0}\left[\mathrm{~A}^{+}\right](0.92)$ \\
\hline \multirow{2}{*}{$77380^{\mathrm{a}}$} & $4 \mathrm{~s} 2^{1}\left[\mathrm{X}^{+}\right](0.93)$ & 86755 & $7 \mathrm{~d} 2^{1}\left[\mathrm{X}^{+}\right](0.09)$ & 101280 & $5 \mathrm{~d}^{\prime} 0^{0}\left[\mathrm{~A}^{+}\right](-0.19)$ \\
\hline & $4 \mathrm{p} 0^{0}\left[\mathrm{X}^{+}\right](0.60)$ & 86873 & $8 \mathrm{~s} 2^{1}\left[\mathrm{X}^{+}\right](0.90)$ & 101458 & $5 \mathrm{~d} 6^{1}\left[\mathrm{~A}^{+}\right](0.09)$ \\
\hline \multirow{2}{*}{$79552^{\mathrm{a}}$} & $4 \mathrm{~d} 0^{0}\left[\mathrm{X}^{+}\right](0.13)$ & 87022 & $8 \mathrm{p} 2^{1}\left[\mathrm{X}^{+}\right](0.64)$ & \multirow{2}{*}{$101753^{\mathrm{a}}$} & $6 \mathrm{p} 0^{0}\left[\mathrm{~A}^{+}\right](0.48)$ \\
\hline & $4 \mathrm{p} 2^{1}\left[\mathrm{X}^{+}\right](0.60)$ & 88076 & $3 \mathrm{p} 0^{0}\left[\mathrm{~A}^{+}\right](0.48)$ & & $6 \mathrm{~s} 6^{1}\left[\mathrm{~A}^{+}\right](0.92)$ \\
\hline 79745 & $3 \mathrm{~s} 0^{0}\left[\mathrm{~A}^{+}\right](0.93)$ & 88740 & $3 \mathrm{p} 6^{1}\left[\mathrm{~A}^{+}\right](0.48)$ & 101970 & $5 \mathrm{~d}^{\prime} 6^{1}\left[\mathrm{~A}^{+}\right](-0.21)$ \\
\hline 80244 & $5 \mathrm{~s} 0^{0}\left[\mathrm{X}^{+}\right](0.93)$ & 90250 & $3 \mathrm{p} 2^{1}\left[\mathrm{~A}^{+}\right](0.49)$ & 102175 & $6 \mathrm{~d} 0^{0}\left[\mathrm{~A}^{+}\right](0.12)$ \\
\hline 81230 & $5 \mathrm{p} 0^{0}\left[\mathrm{X}^{+}\right](0.59)$ & 91503 & $3 \mathrm{~d} 0^{0}\left[\mathrm{~A}^{+}\right](0.19)$ & 102385 & $7 \mathrm{~s} 0^{0}\left[\mathrm{~A}^{+}\right](0.92)$ \\
\hline 81688 & $4 \mathrm{~d} 2^{1}\left[\mathrm{X}^{+}\right](0.14)$ & 92161 & $3 \mathrm{~d} 6^{1}\left[\mathrm{~A}^{+}\right](0.18)$ & 102495 & $6 \mathrm{~d}^{\prime} 0^{0}\left[\mathrm{~A}^{+}\right](-0.20)$ \\
\hline 82320 & $5 \mathrm{~d} 0^{0}\left[\mathrm{X}^{+}\right](0.09)$ & 93180 & $4 \mathrm{~s} 0^{0}\left[\mathrm{~A}^{+}\right](1.00)$ & 102860 & $6 \mathrm{~d} 6^{1}\left[\mathrm{~A}^{+}\right](0.10)$ \\
\hline 82395 & $5 \mathrm{~s} 2^{1}\left[\mathrm{X}^{+}\right](0.94)$ & 93710 & $3 \mathrm{~d} 2^{1}\left[\mathrm{~A}^{+}\right](0.19)$ & \multirow{2}{*}{$103040^{\mathrm{a}}$} & $7 \mathrm{~d} 0^{0}\left[\mathrm{~A}^{+}\right](0.11)$ \\
\hline 82600 & $6 \mathrm{~s} 0^{0}\left[\mathrm{X}^{+}\right](0.93)$ & 93830 & $4 \mathrm{~s} 6^{1}\left[\mathrm{~A}^{+}\right](1.00)$ & & $7 \mathrm{~s} 6^{1}\left[\mathrm{~A}^{+}\right](0.92)$ \\
\hline 83063 & $6 \mathrm{p} 0^{0}\left[\mathrm{X}^{+}\right](0.63)$ & 94520 & $3 \mathrm{~d}^{\prime} 0^{0}\left[\mathrm{~A}^{+}\right](-0.18)$ & \multirow{2}{*}{$103165^{\mathrm{a}}$} & $8 \mathrm{~s} 0^{0}\left[\mathrm{~A}^{+}\right](0.92)$ \\
\hline 83374 & $5 \mathrm{p} 2^{1}\left[\mathrm{X}^{+}\right](0.60)$ & 95205 & $3 \mathrm{~d}^{\prime} 6^{1}\left[\mathrm{~A}^{+}\right](-0.19)$ & & $6 \mathrm{~d}^{\prime} 6^{1}\left[\mathrm{~A}^{+}\right](-0.21)$ \\
\hline 83700 & $6 \mathrm{~d} 0^{0}\left[\mathrm{X}^{+}\right](0.12)$ & 95430 & $4 \mathrm{~s} 2^{1}\left[\mathrm{~A}^{+}\right](1.00)$ & 103230 & $7 \mathrm{~d}^{\prime} 0^{0}\left[\mathrm{~A}^{+}\right](-0.19)$ \\
\hline 83873 & $7 \mathrm{~s} 0^{0}\left[\mathrm{X}^{+}\right](0.95)$ & 96590 & $4 \mathrm{p} 0^{0}\left[\mathrm{~A}^{+}\right](0.46)$ & 103665 & $9 \mathrm{~s} 0^{0}\left[\mathrm{~A}^{+}\right](0.94)$ \\
\hline 84152 & $7 \mathrm{p} 0^{0}\left[\mathrm{X}^{+}\right](0.65)$ & 96820 & $3 \mathrm{~d}^{\prime} 2^{1}\left[\mathrm{~A}^{+}\right](-0.19)$ & 112100 & $4 \mathrm{~d} 0^{0}\left[\mathrm{C}^{+}\right](0.12)$ \\
\hline \multirow{2}{*}{$84539^{\mathrm{a}}$} & $7 \mathrm{~d} 0^{0}\left[\mathrm{X}^{+}\right](0.14)$ & 97295 & $4 \mathrm{p} 6^{1}\left[\mathrm{~A}^{+}\right](0.45)$ & 113760 & $4 \mathrm{~d} 8^{1}\left[\mathrm{C}^{+}\right](0.10)$ \\
\hline & $5 \mathrm{~d} 2^{1}\left[\mathrm{X}^{+}\right](0.07)$ & 98160 & $4 \mathrm{~d} 0^{0}\left[\mathrm{~A}^{+}\right](0.09)$ & 114705 & $5 \mathrm{~d} 0^{0}\left[\mathrm{C}^{+}\right](0.16)$ \\
\hline 84665 & $8 \mathrm{~s} 0^{0}\left[\mathrm{X}^{+}\right](0.95)$ & 98670 & $50^{0}\left[\mathrm{~A}^{+}\right](0.95)$ & 116160 & $6 \mathrm{~d} 0^{0}\left[\mathrm{C}^{+}\right](0.17)$ \\
\hline \multirow{2}{*}{$84823^{\mathrm{a}}$} & $8 \mathrm{p} 0^{0}\left[\mathrm{X}^{+}\right](0.68)$ & \multirow{2}{*}{$98810^{\mathrm{a}}$} & $4 \mathrm{~d} 6^{1}\left[\mathrm{~A}^{+}\right](0.10)$ & 117050 & $7 \mathrm{~d} 0^{0}\left[\mathrm{C}^{+}\right](0.15)$ \\
\hline & $6 \mathrm{~s} 2^{1}\left[\mathrm{X}^{+}\right](0.90)$ & & $4 \mathrm{p} 2^{1}\left[\mathrm{~A}^{+}\right](0.47)$ & 117610 & $8 \mathrm{~d} 0^{0}\left[\mathrm{C}^{+}\right](0.15)$ \\
\hline 85088 & $8 \mathrm{~d} 0^{0}\left[\mathrm{X}^{+}\right](0.16)$ & 99135 & $4 \mathrm{~d}^{\prime} 0^{0}\left[\mathrm{~A}^{+}\right](-0.20)$ & & \\
\hline 85180 & $9 \mathrm{~s} 0^{0}\left[\mathrm{X}^{+}\right](0.95)$ & 99335 & $5 \mathrm{~s} 6^{1}\left[\mathrm{~A}^{+}\right](0.95)$ & & \\
\hline
\end{tabular}




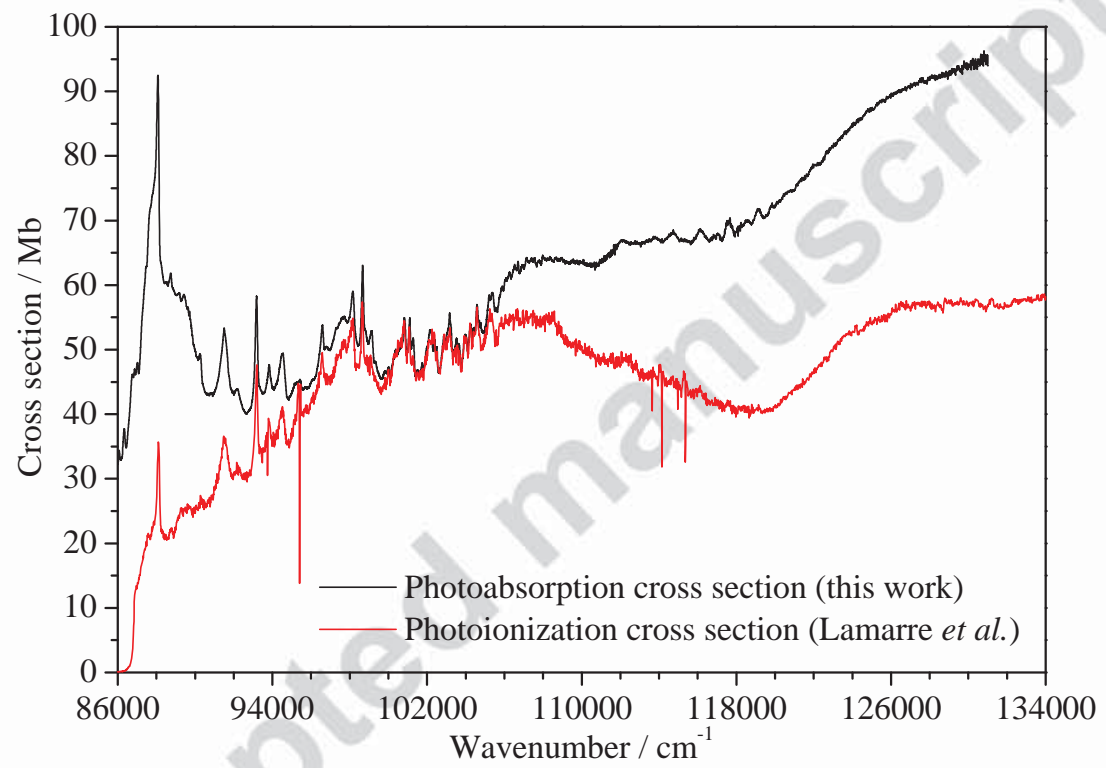

Figure 8: Tentative scaling of the $\mathrm{CH}_{3} \mathrm{C}_{3} \mathrm{~N}^{+}$ion yield measured by Lamarre et al. [17] (red line) on an absolute cross section scale using its photoabsorption cross section measured in the present work (black line) (see text for details). 
ily be explained by invoking the opening of dissociative ionization channels of $\mathrm{CH}_{3} \mathrm{C}_{3} \mathrm{~N}$. Indeed, at this wavenumber the dissociative ionization process starts to be non-negligible (see Ref. [17]). Note that the ion yield reported in Ref. [17] only corresponds to the $\mathrm{CH}_{3} \mathrm{C}_{3} \mathrm{~N}^{+}$parent cation signal and does not represent the total ion yield including the ionic fragments produced by dissociative ionization.

\section{Conclusion}

Absolute photoabsorption cross section of methylcyanoacetylene has been recorded for the first time over the $44500-130000 \mathrm{~cm}^{-1}$ range using the Fouriertransform spectrometer of the DESIRS beamline at SOLEIL synchrotron facility. Only the low energy range of our measurement in the region of a valence state transition has been published previously [5]. In this work, we propose a new and complete assignment of the vibrational progressions observed for this transition. A first assignment of the Rydberg series converging to different electronic states of the cation is also proposed. Preliminary calculations have been performed by TD-DFT method to support the analysis but more sophisticated calculations are needed to provide a deeper insight into the highly-excited electronic structure of methylcyanoacetylene.

From the structure intensities observed above the first ionization potential in our absorption spectrum and in the $\mathrm{CH}_{3} \mathrm{C}_{3} \mathrm{~N}^{+}$photoion yield previously measured in our group [17], we conclude that the ionization yield in the $100000-$ $105000 \mathrm{~cm}^{-1}$ range is close to unity which allows a scaling of the parent ion yield on an absolute cross section scale.

The high-quality of the absorption spectrum reported in the present work will be of great help to validate future high-level $a b$ initio calculations of the complex excited electronic structure of this molecule. 


\section{Acknowledgments}

We are indebted to the general staff of the SOLEIL synchrotron facility for their support. This work was performed on the DESIRS beamline under proposal number 20131243. The authors are grateful to Dr. Denis Joyeux for his help with the acquisition program. L.A.V.M. gratefully acknowledges Paris- Sud University for a 1-month invited professorship. J.-C.G. thanks the Centre National d'Études Spatiales (CNES) for a grant and the CNRS program Physique et Chimie du Milieu Interstellaire (PCMI) for financial support. R.K. and M.G. acknowledge the support from the National Science Centre (Poland), project N. 2011/03/B/ST4/02763.

\section{Appendix A. Plot of the absorption cross section versus $n^{*}$}

A plot example of the absorption cross section against the effective quantum number $\left(n^{*}\right)$ is presented here for the Rydberg series converging to the $365 \tilde{\mathrm{X}}^{+}{ }^{2} \mathrm{E}\left(v^{+}=0\right)$ ground state of $\mathrm{CH}_{3} \mathrm{C}_{3} \mathrm{~N}^{+}$. This plot allows to vertically visualize the different members of a pure Rydberg series (without any interaction). Note that the panel corresponding to the $n^{*} \in[2 ; 3]$ range is displayed to show that the 3s Rydberg state (identified by TD-DFT calculations) is probably perturbed by a Herzberg-Teller interaction with the close-lying valence state.

\section{Appendix B. Supplementary material}

Supplementary figures associated with this paper and displaying the complete Rydberg series assignment can be found in the online version at XXXX.

\section{References}

[1] N. W. Broten, J. M. MacLeod, L. W. Avery, W. M. Irvine, B. Höglund, P. Friberg, A. Hjalmarson, The detection of interstellar methylcyanoacetylene, The Astrophysical Journal Letters 276 (1984) L25-L29. doi:10. $1086 / 184181$. 

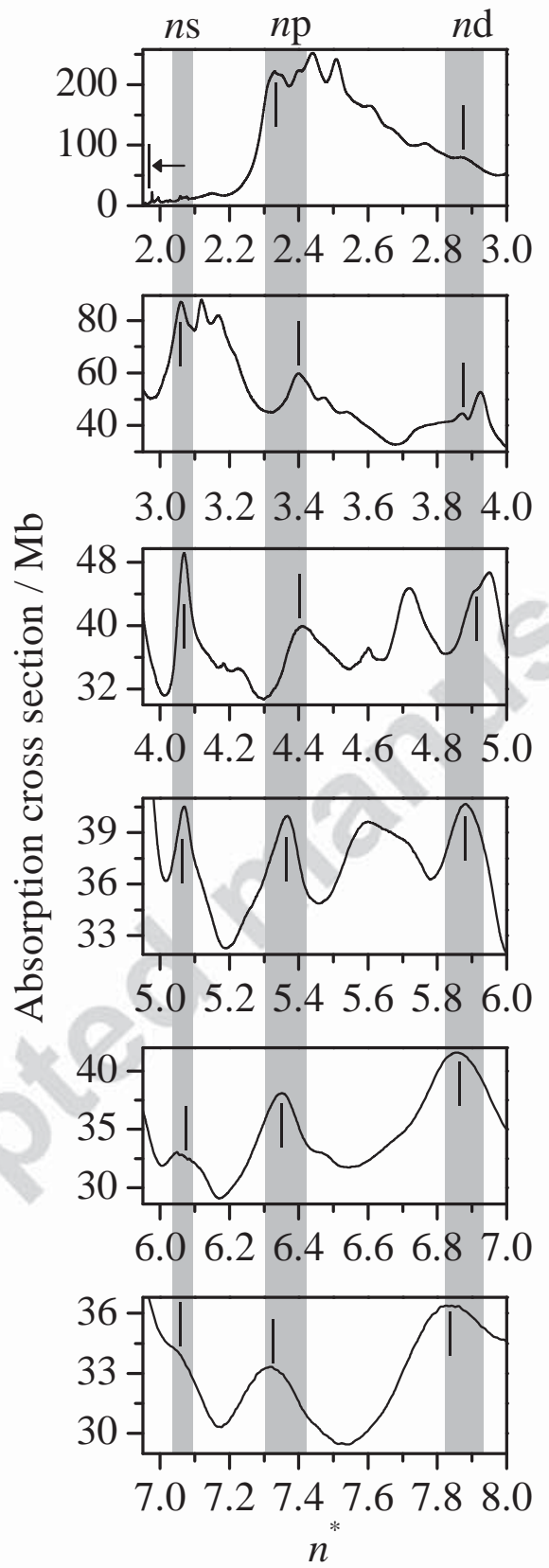

Figure A.1: Plot of the absorption cross section of methylcyanoacetylene against the effective quantum number $n^{*}\left(n^{*}=n-\delta\right)$ for the Rydberg series converging to the $\tilde{\mathrm{X}}^{+}{ }^{2} \mathrm{E}\left(v^{+}=\right.$ 0) state of $\mathrm{CH}_{3} \mathrm{C}_{3} \mathrm{~N}^{+}$. The gray areas link vertically bands with approximately the same quantum defect $(\delta)$ for each value of the principal quantum number $(n)$. Each selected band is located by a vertical stick. The arrow in the upper panel shows that the 3s state is located at a slightly lower energy than expected, probably due to an interaction with the $3{ }^{1} \mathrm{~A}_{1}$ valence state (see section 4). 
[2] A. Belloche, H. S. P. Müller, K. M. Menten, P. Schilke, C. Comito, Complex organic molecules in the interstellar medium: IRAM $30 \mathrm{~m}$ line survey of Sagittarius B2(N) and (M), Astronomy \& Astrophysics 559 (2013) A47. doi:10.1051/0004-6361/201321096.

[3] A. J. Remijan, F. Wyrowski, D. N. Friedel, D. S. Meier, L. E. Snyder, A Survey of Large Molecules toward the Proto-Planetary Nebula CRL 618, The Astrophysical Journal 626 (1) (2005) 233-244. doi:10.1086/429750.

[4] F. Cerceau, F. Raulin, R. Courtin, D. Gautier, Infrared spectra of gaseous mononitriles: Application to the atmosphere of Titan, Icarus 62 (2) (1985) 207-220. doi:10.1016/0019-1035(85)90118-6.

[5] P. Bruston, H. Poncet, F. Raulin, C. Cossart-Magos, R. Courtin, UV spectroscopy of Titan's atmosphere, planetary organic chemistry, and prebiological synthesis: I. Absorption spectra of gaseous propynenitrile and 2butynenitrile in the 185- to 250-nm region, Icarus 78 (1) (1989) 38-53. doi:10.1016/0019-1035(89)90068-7.

[6] M. Khlifi, F. Raulin, Infrared intensities and frequencies of 2-butynenitrile: Application to the atmosphere of Titan, Spectrochimica Acta Part A: Molecular Spectroscopy 47 (2) (1991) 171-176. doi:10.1016/ 0584-8539(91) 80088-Z.

[7] N. Dello Russo, R. K. Khanna, Laboratory Infrared Spectroscopic Studies of Crystalline Nitriles with Relevance to Outer Planetary Systems, Icarus 123 (2) (1996) 366-395. doi:10.1006/icar.1996.0165.

[8] V. Vuitton, R. V. Yelle, M. J. McEwan, Ion chemistry and N-containing molecules in Titan's upper atmosphere, Icarus 191 (2) (2007) 722-742. doi:10.1016/j.icarus.2007.06.023.

[9] L. E. Snyder, J. M. Hollis, P. R. Jewell, F. J. Lovas, A. Remijan, Confirmation of Interstellar Methylcyanodiacetylene $\left(\mathrm{CH}_{3} \mathrm{C}_{5} \mathrm{~N}\right)$, The Astrophysical Journal 647 (1) (2006) 412-417. doi:10.1086/505323. 
[10] J. Sheridan, L. F. Thomas, Microwave Spectrum of Methyl-Cyanoacetylene, Nature 174 (1954) 798. doi:10.1038/174798a0.

[11] A. Moïses, D. Boucher, J. Burie, J. Demaison, A. Dubrulle, Millimeterwave spectrum of methylcyanoacetylene, Journal of Molecular Spectroscopy 92 (2) (1982) 497-498. doi:10.1016/0022-2852(82)90118-7.

[12] M. Bester, M. Tanimoto, B. Vowinkel, G. Winnewisser, K. Yamada, Rotational spectrum of methylcyanoacetylene. A new millimiter wave spectrometer, Zeitschrift Für Naturforschung Section A-A Journal of Physical Sciences 38 (1) (1983) 64-67. doi:10.1515/zna-1983-0112.

[13] K. M. T. Yamada, M. Bester, M. Tanimoto, G. Winnewisser, Pure rotational spectrum of cyanopropyne in the $v_{12}=1$ vibrational state, Journal of Molecular Spectroscopy 126 (1) (1987) 118-128. doi:10.1016/ 0022-2852(87) 90082-8.

[14] R. Tubino, G. Dellepiane, G. Zerbi, Vibrational Spectrum and VibroRotational Analysis of Cyanopropyne, The Journal of Chemical Physics 50 (2) (1969) 621-627. doi:10.1063/1.1671109.

[15] G. Bieri, E. Heilbronner, V. Hornung, E. Kloster-Jensen, J. P. Maier, F. Thommen, W. von Niessen, Electronic states of substituted haloacetylene and cyanoacetylene radical cations, Chemical Physics 36 (1) (1979) 1-14. doi:10.1016/0301-0104(79)85099-5.

[16] L. Åsbrink, W. von Niessen, G. Bieri, 30.4-nm He(II) Photoelectron spectra of organic molecules: Part II. Aza-compounds (C, H, N), Journal of Electron Spectroscopy and Related Phenomena 21 (1) (1980) 93-101. doi : 10.1016/0368-2048(80)85039-0.

${ }_{430}[17]$ N. Lamarre, C. Falvo, C. Alcaraz, B. Cunha de Miranda, S. Douin, A. Flütsch, C. Romanzin, J.-C. Guillemin, S. Boyé-Péronne, B. Gans, Photoionization spectroscopy of $\mathrm{CH}_{3} \mathrm{C}_{3} \mathrm{~N}$ in the vacuum-ultraviolet range, 
Journal of Molecular Spectroscopy 315 (2015) 206-216. doi:10.1016/j. jms. 2015.03.005.

[18] J. Fulara, S. Leutwyler, J. P. Maier, U. Spittel, Electronic absorption spectra of cyanogen cation $\left(\mathrm{NCCN}^{+}\right)$, cyanoacetylene cation $\left(\mathrm{HCCCN}^{+}\right)$, and methylcyanoacetylene cation $\left(\mathrm{MeCCCN}^{+}\right)$in neon matrixes, The Journal of Physical Chemistry 89 (15) (1985) 3190-3193. doi:10.1021/j100261a004.

[19] L. Nahon, N. de Oliveira, G. A. Garcia, J.-F. Gil, B. Pilette, O. Marcouillé, B. Lagarde, F. Polack, DESIRS: a state-of-the-art VUV beamline featuring high resolution and variable polarization for spectroscopy and dichroism at SOLEIL, Journal of Synchrotron Radiation 19 (4) (2012) 508-520. doi: 10.1107/S0909049512010588.

[20] N. de Oliveira, M. Roudjane, D. Joyeux, D. Phalippou, J.-C. Rodier, L. Nahon, High-resolution broad-bandwidth Fourier-transform absorption spectroscopy in the VUV range down to $40 \mathrm{~nm}$, Nature Photonics 5 (3) (2011) 149-153. doi:10.1038/nphoton.2010.314.

[21] N. de Oliveira, D. Joyeux, M. Roudjane, J. F. Gil, B. Pilette, L. Archer, K. Ito, L. Nahon, The high resolution absorption spectroscopy branch on the VUV beamline DESIRS at SOLEIL, Journal of Synchrotron Radiation 23 (2016) x-x. doi:10.1107/S1600577516006135.

[22] M. J. Frisch, G. W. Trucks, H. B. Schlegel, G. E. Scuseria, M. A. Robb, J. R. Cheeseman, G. Scalmani, V. Barone, B. Mennucci, G. A. Petersson, H. Nakatsuji, M. Caricato, X. Li, H. P. Hratchian, A. F. Izmaylov, J. Bloino, G. Zheng, J. L. Sonnenberg, M. Hada, M. Ehara, K. Toyota, R. Fukuda, J. Hasegawa, M. Ishida, T. Nakajima, Y. Honda, O. Kitao, H. Nakai, T. Vreven, J. A. Montgomery Jr., J. E. Peralta, F. Ogliaro, M. Bearpark, J. J. Heyd, E. Brothers, K. N. Kudin, V. N. Staroverov, R. Kobayashi, J. Normand, K. Raghavachari, A. Rendell, J. C. Burant, 
R. E. Stratmann, O. Yazyev, A. J. Austin, R. Cammi, C. Pomelli, J. W. Ochterski, R. L. Martin, K. Morokuma, V. G. Zakrzewski, G. A. Voth, P. Salvador, J. J. Dannenberg, S. Dapprich, A. D. Daniels, Ö. Farkas, J. B. Foresman, J. V. Ortiz, J. Cioslowski, D. J. Fox, Gaussian 09 Revision D.01.

[23] T. Yanai, D. P. Tew, N. C. Handy, A new hybrid exchange-correlation functional using the Coulomb-attenuating method (CAM-B3LYP), Chemical Physics Letters 393 (1-3) (2004) 51-57. doi:10.1016/j.cplett.2004. 06.011.

[24] T. H. Dunning, Gaussian basis sets for use in correlated molecular calculations. I. The atoms boron through neon and hydrogen, The Journal of Chemical Physics 90 (2) (1989) 1007-1023. doi:10.1063/1.456153.

[25] R. A. Kendall, T. H. Dunning, R. J. Harrison, Electron affinities of the firstrow atoms revisited. Systematic basis sets and wave functions, The Journal of Chemical Physics 96 (9) (1992) 6796-6806. doi:10.1063/1.462569.

[26] R. Bauernschmitt, R. Ahlrichs, Treatment of electronic excitations within the adiabatic approximation of time dependent density functional theory, Chemical Physics Letters 256 (4-5) (1996) 454-464. doi:10.1016/ 0009-2614 (96) 00440-x.

${ }_{480}$ [27] M. E. Casida, C. Jamorski, K. C. Casida, D. R. Salahub, Molecular excitation energies to high-lying bound states from time-dependent densityfunctional response theory: Characterization and correction of the timedependent local density approximation ionization threshold, The Journal of Chemical Physics 108 (11) (1998) 4439-4449. doi:10.1063/1.475855.

[28] C. Van Caillie, R. D. Amos, Geometric derivatives of excitation energies using SCF and DFT, Chemical Physics Letters 308 (3-4) (1999) 249-255. doi:10.1016/s0009-2614(99)00646-6.

[29] C. Van Caillie, R. D. Amos, Geometric derivatives of density functional theory excitation energies using gradient-corrected functionals, Chemical 
[30] F. Furche, R. Ahlrichs, Adiabatic time-dependent density functional methods for excited state properties, The Journal of Chemical Physics 117 (16) (2002) 7433-7447. doi:10.1063/1.1508368.

495 [31] G. Scalmani, M. J. Frisch, B. Mennucci, J. Tomasi, R. Cammi, V. Barone, Geometries and properties of excited states in the gas phase and in solution: theory and application of a time-dependent density functional theory polarizable continuum model, The Journal of Chemical Physics 124 (9) (2006) 94107. doi:10.1063/1.2173258.

[32] R. E. Connors, J. L. Roebber, K. Weiss, Vacuum ultraviolet spectroscopy of cyanogen and cyanoacetylenes, The Journal of Chemical Physics 60 (12) (1974) 5011-5024. doi:10.1063/1.1681016.

[33] S. Leach, G. A. Garcia, A. Mahjoub, Y. Bénilan, N. Fray, M.-C. Gazeau, F. Gaie-Levrel, N. Champion, M. Schwell, Ionization photophysics and spectroscopy of cyanoacetylene, The Journal of Chemical Physics 140 (17) (2014) 174305. doi:10.1063/1.4871298.

[34] Y. Bénilan, A. Jolly, F. Raulin, J.-C. Guillemin, IR band intensities of $\mathrm{DC}_{3} \mathrm{~N}$ and $\mathrm{HC}_{3}^{15} \mathrm{~N}$ : implication for observations of Titan's atmosphere, Planetary and Space Science 54 (6) (2006) 635-640. doi:10.1016/j.pss. 2006.01 .006 .

[35] V. A. Job, G. W. King, The electronic spectrum of cyanoacetylene: Part II. Analysis of the 2300-Å system, Journal of Molecular Spectroscopy 19 (1-4) (1966) 178-184. doi:10.1016/0022-2852(66)90239-6.

[36] M. Turowski, C. Crépin, M. Gronowski, J.-C. Guillemin, A. Coupeaud, I. Couturier-Tamburelli, N. Piétri, R. Kołos, Electronic absorption and phosphorescence of cyanodiacetylene, The Journal of Chemical Physics 133 (7) (2010) 074310. doi:10.1063/1.3472978. 
[37] G. J. Cartwright, D. O'Hare, A. D. Walsh, P. A. Warsop, The rotational and vibrational structure of the $2500 \AA$ system of cyanogen, Journal of Molecular Spectroscopy 39 (3) (1971) 393-399. doi:10.1016/ 0022-2852(71)90210-4.

[38] F. A. Miller, R. B. Hannan Jr., The ultraviolet absorption spectrum of dicyanoacetylene, Spectrochimica Acta 12 (4) (1958) 321-331. doi:10. 1016/0371-1951(58)80058-2.

[39] M. Turowski, U. Szczepaniak, T. Custer, M. Gronowski, J.-C. Guillemin, R. Kołos, Electronic spectroscopy of methylcyanodiacetylene $\left(\mathrm{CH}_{3} \mathrm{C}_{5} \mathrm{~N}\right)$, ChemPhysChem (2016) (in preparation). 